\title{
A Luz em Claudino
}

\author{
Leon Kossovitch*
}

Resumo: A pintura da luz de José Claudino da Nóbrega propõe reflexão heurística: luz indivisa e luz da coisa são refletidas analogicamente na história de doutrinas e artes diversas. O Século de Justiniano tem realce: as ecfrases de panegírico, as articulações de metafísica e, principalmente, os mosaicos de ouro que então se produzem distinguem a téssera. Simultaneamente cubo, senha e jogo, a téssera é o análogo principal da pintura da luz indivisa, oposta à luz determinada. Palavras-chave: Luz - téssera - pintura - olhar - reflexão - heurística - forma - coisa indivisibilidade - distribuição - intensidade.

Os cubos dividem a pintura, pois ou a fecham em chave, respingos abstratos ou figurativos, op-artísticos ou genericamente reticulados - do divisionismo, atualizado como procedimento imediato, ou a abrem como meditação, mediação da inatual arte musiva. A luz que se gera com cubos aparece embaçada na claridade das classes vigentes, escurecedoras da reflexão porquanto fascinadas pelo procedimento técnico; contudo, a pintura pode refratar a atualidade e, atual, refletir sobre o feixe de suas visadas, propagando a sua luz na luz tesserária. Não se tendo José Claudino da Nóbrega convertido aos usos correntes, seu cubo, tessera, mira-se na tesseraria, arte antiga dos embutidos, que cintila, longínqua, como a mediadora que aproxima a luz a si mesma. O pintor está no foco da luz, memorável momento, em que o olhar se desvia da coisa e incendeia com a luz indivisa o divisionismo e suas atualizações. Enquanto declina a luz instrumentalizada, a reflexão decompõe-se no prisma

*Professor de Estética no Departamento de Filosofia da USP. 
de seus possíveis: discurso da luz indivisa, ela se tem como dividida e, sequencial, supõe-se adequadamente dividida quando ziguezagueia como ventura de lances o seu curso. Vôo de mosca que diagrama reflexos, a reflexão, atraída pela luz, é heurística e seu traçado analógico cruza a história. Heuristicamente, lança-se a analogia das tésseras, das pintadas e das vítreas, da pintura da luz e da arte do mosaico; refletindo-se uma na outra, distinguem-se, logo, a matéria e seus efeitos. A visada ao cubo helenístico, romano e, principalmente, bizantino separa, aproximando-os, a antiguidade distante e este momento. Sendo patente a material, outra distinção divisa-se: enquanto no mosaico a luz engendra cores variegadas, efeito de ângulos multiplicados por superfícies irregulares de cubos e suportes - parede, abóbada, cúpula —, nos quais aqueles estão embutidos, na pintura de Claudino amplo espectro é gerado da interação cromática de cubos e fundos. No vidro, a cor é processão da luz que a irregularidade dirige; na pintura, a luz é filha da regularidade das películas de cor. A diferença é gerativa: próxima da arte antiga, a pintura é dela distanciada quando se reflete sobre a ordem em que se geram a luz e a cor.

A inflexão de Claudino evidencia-se como deslocamento daquilo a que hoje se chama "ilusionismo verista", demonstrada na antiguidade de Plínio o Velho no elogio. Com a maravilha, o gênero expõe a pintura imitadora da natureza, mostrando o olhar, como o do pássaro e do cavalo, do homem logrado ao tomar por verdadeiro o artifício; a semelhança, demonstrada no gênero por amplificação mirabolante, admira-se no Império como certame da pintura e da natureza enquanto erro e verdade indiscerníveis. Usada na construção da coisa que engana, a luz distingue-a com a distância, modela-a com o claro-escuro, dá-lhe lustre e reflexividade (na maravilha de Plínio se concentram conhecimentos pictóricos que se expandem, menos como maravilha, mais como ciência, no século XV e no início do XVI, sendo expostos em Leonardo pormenorizadamente. Pintura, em que a luz é princípio, o impressionismo não diminui tais pressupostos, antes os amplia). Intrumentalizada, a luz não se acende para a pintura como luz: absorvida pela coisa como seu requisito, não pode exibir-se indivisa.

Dessa dilatada servidão diverge o Século de Justiniano: lancem-se os olhos na iluminação de Santa Sofia e nos escritos laudatórios da mesma, das 
Kossovitch, L., discurso (20), 1993: 137-146

mãos de Procópio de Gaza e Paulo Silenciário. No panegírico de Paulo, a extensa descrição do templo magnifica-o com a intensa radiação do léxico da luz: tudo nele brilha, fulge, reverbera, cintila, esplende; na de Procópio, da comparação do sol e das luzes interiores, estas saem ilustradas, reverberantes no ouro musivo, onde os pormenores, dançando à roda, apagam-se na luz que atira a visão para alto-além: "as centelhas da luz impedem o espectador de deter sua visão nos pormenores; cada um deles atrai a visão e a conduz a outro. $\mathrm{O}$ movimento circular da visão reproduz-se ao infinito, pois o espectador nunca é capaz de eleger em todo o conjunto o que seja de sua preferência... O espectador eleva-se a Deus e flutua nos ares". Da atenção ao êxtase, do aqui ao além, do finito ao infinito, do gerado ao gerador; metafísica, a ecfrase de Procópio é dirigida por doutrina neoplatônica, decerto a de Plotino, muito certeira: a visão da coisa é ofuscada na ascese da alma à hipóstase superior, Inteligência, ou luz que se vê, Luz, a si mesma, da qual a mesma alma ainda se alça à hipóstase do Um, Deus de Procópio, cimo da contemplação. (luz e sol esplendem metafísica e retoricamente tanto no discurso religioso quanto em discursos com este aparentados, como no mesmo Plotino, no matricial pseudoAreopagita, em muitos autores cristãos primitivos e em muitos coetâneos seus, gnósticos, no solar imperador Juliano, que defendem modalidades platonizantes em conjunção com outras luzes, as do Avesta, de Zaratustra). Em Procópio, o determinado, pormenor - coisa —, é superado; dele desviando a alma, a luz a dirige para o indeterminado do êxtase; por isso, a luz é rebatida para longe da maravilha pliniana, em cuja indiscernibilidade admirável de construto e natureza se celebra uma história de longuíssima duração. A luz bizantina e neoplatônica está em campo iconográfico distinto do da coisa por ela gerada, pois, geradora, é a esta superior. Heuristicamente, a metafísica da luz é considerada pelos cubos de Claudino: quando ele se desvia da natureza morta e da paisagem, que vinha pintando, não pode mais visar à luz da coisa e, distanciadora, modeladora, lustradora, esta cobre-se de sombra, desaparecendo sob outra, que se acende para a reflexão.

A distinção de luz instrumentalizada e luz indivisa ordena a pintura, relativamente à qual se discorre sobre $\mathrm{a}$ ascese de Claudino. Veja-se a pintura-op: dirigida por luz ilusionista, não se distingue ela, apesar do império da geo- 
metria, da que imita a natureza, assim, da que divide a luz. Outros sentidos expõem-se na pintura do rarefeito, vapores, fumaças, neblinas, de Turner, ou na do brilho, tremeluzência de paisagens de Constable. A coisa ganha generalidade e, com ela, o anteparo, estreito e rígido no século XV e começo do XVI. Além do anteparo, a fonte, na qual a luz é determinada pela coisa de que emana: na investigação luminista, cuja fonte assinalável é o Rafael das Stanze, brilha La Tour, em quem se acresce à luz da fonte o seu efeito na carne, revelada transparência. Estendendo as propriedades da coisa iluminada na coisa iluminadora e na coisa translúcida, a luz não aparece indivisa. Redividindo a coisa, tais propriedades estão ausentes da visada de Claudino, em quem anteparo (mesmo o biface, a um tempo opaco e transparente) e fonte presente são apagados. Por isso, a sua luz diverge da coisa, reaparecendo heuristicamente Plotino: a luz é Luz na hipóstase da Inteligêngia, do Ser e do Belo, sendo a coisa afastada como matéria, por genérica que seja quanto às suas propriedades; tampouco sobem à hipóstase a imitação da natureza e as regras retoras da arte, como a simetria (proporções), central nas canônicas ditas "clássicas" e, apesar das restrições por vezes feitas, "helenísticas”. Todavia, por próxima que seja conceitualmente da Luz, indivisa como idêntica a si mesma, a pintura não a pode considerar, pois, tendo embora ambas a luz sem partilha, a de Plotino não pertence, por inteligível, à luz, nem a pintura de Claudino, à Luz.

A luz indivisa pode ainda ser captada pela pintura da subjetividade, que, diminuindo a imitação e a conexa eloquência da ilusão, sublima-se como princípio uno, indivisível. Com o século XIX, a pintura pode ser adjudicada ao sujeito, romântico ou expressionista, que nela se pretende expresso enquanto expurga da coisa aquilo que nela tem como exterioridade mecânica, indeterminação. Em tal visão, interior, desligada a luz da coisa assim exteriorizada, a indivisibilidade é tida como orgânica e centrada em sujeito sentimental. Desgarrada da coisa exterior, a luz postulada indivisa, aderindo ao sentimento, depende inteiramente de seu arbítrio; legisferante, o sujeito autônomo exprime-se, mas o expresso não ultrapassa a coisa mesma, pois preestabelecida pelo avesso, as determinações do interior. A autonomia do sujeito expressivo institui a luz determinada, relativamente a ele heterônoma. Modalizando-se a autonomia, suas extensões multiplicam-se: explicita-o a abstração, ora toda ela 
Kossovitch, L., discurso (20), 1993: 137-146

subjetivada (e que apela, quando busca índices de suposta objetividade, para o etéreo de títulos tirados a léxico cósmico-astronômico), ora, fugindo ao talante da subjetividade, fundada em gramática, como em Kandinsky, na qual volta, dada a autonomia da pintura frente ao objeto e a refringência sua atrás do sujeito, o domínio canônico antes vigente, analogia musical. Dessas divisões, que afetam a luz, segue-se oposição de uso recente: a da realidade (da representação, do exterior, com que se padroniza em chave naturalista-realista o campo múltiplo da imitação) e a do simbólico (que defende ora a representação interna contra a externa, determinando-a como expressão, ora o convencionalismo, generalizado, assim, anti-histórico, de toda a pintura). Impositiva nos anos 30 na crítica e historiografia, tal disjuntiva institui convencionalismo (que inclui em seu escopo tudo, assim, os mesmos naturalismo e realismo) inaplicável à luz indivisa: irredutível à convenção e à subjetividade, a luz de Claudino faz refletir em outro sentido. Não sendo subjetiva, simbólica ou canônica, sua visada desloca arbítrio sentimental, motivação subjetiva, domínio preceitual, instâncias, também estes, da coisa determinada por dentro. Nada é mais atraente - a mosca busca a luz - do que firmar a visada que, pelo menos, tem como possível a pintura da luz. Todavia, outra dificuldade sobrevém: exacerbando-se as exacerbadas posturas da subjetividade repassadas acima, "luz" não é mais que nome, que significa, designando ou não, realidade que esse convencionalismo institui. Luz é, assim, o que se significa como tal no nome; mas a razão nominalista perde, aqui, sua proverbial agudeza, pois, dissemina, preguiçosa, a luz no que o sujeito (ou instância não subjetiva) assim nomeia, desde que a intersubjetividade (ou equivalente desta) o sancione como uso. Em Claudino, nada autoriza a desistência nominalista: como a sua luz não se produz no abstrato ou no simbólico e tampouco do sujeito sentimental, a arbitrariedade nominalista não é menos insatisfatória, pois na luz - a simples referência a ela como tema basta - tem-se visada.

Luz indivisa é idêntica a si mesma, considerada, não nos usos, determinações - expressividade; anteparo, fonte; distância, claro-escuro, brilho, reflexo, transparência; simetria e outros preceitos - , que a fecham na coisa, por fora ou por dentro, mas nos processos. Em si mesma, a luz é bastante genérica para não ser aproximada com noções de fechamento, forma, figura, 
limite, dimensão, enfim, determinação: coisa. Aberta, ela retém o informe, o ilimitado, o indeterminado, o indiviso, desde que, na prefixaçăo negativa, não opere o negado como significado do termo. Considerem-se dois exemplos, que explicitam duas modalidades de negação. Vituperando a curiosidade, - que pode ser referida ao "enigma", topos da antiguidade - na ocorrência os monstros que distraem de Deus o olhar cristianíssimo neles fixado, São Bernardo joga com a antítese de "formosura" e "deformidade": "aquela maravilhosa formosura deformada e formosa deformidade - mira quaedam deformis formositas ac formosa deformitas". O significado da raiz "forma" está ausente do quiasma, embora opere, mais que o som, a etimologia. Na descrição do aniquilamento de militares em fuga pelo deserto da Líbia, o poeta Lucano, pressupondo o significado de "limite", implícito no dimensional "maior", mostra Nasídio, picado por serpente, inchar a ponto de a intumescência superar as dimensões de seu corpo. No passo, espantoso também como espacialização da linguagem, o ilimitado do tumor não suprime o significado de "limite" (poderia ser "forma" etc.), pelo qual é articulado o desmedido na Farsália. Não é, pois, no sentido deste uso que se propõe o significado da prefixação: espacializações, "ilimitado", "informe" etc., têm por termo geral "indeterminado", aqui, "indiviso", que também significam sem manter o negado.

Afastados forma e limite, que compendiam pictoricamente as modalidades de determinação afloradas acima, a luz indivisa aparece, a um tempo, como abertura e visada. Abertura de generalidade, que não se confunde com pureza, simplicidade (lembre-se, de passagem, a física, na qual a luz se enuncia como complexa e contraditória, sendo nela consideradas complementares as duas interpretações, partícula e onda, descontínuo e contínuo), a luz é, como indivisa, indeterminada. Na abertura, a visada, iconograficamente dirigida: sem título, o visado impóe-se ao olhar, que o reconhece; cada tela opera, assim, como senha, outro significado de tessera, sem que, com isso, seja estereotipada a pintura. É como senha que o cubo de Claudino opera reconhecimento, sendo convergentes tanto a multiplicidade de olhares quanto a multiplicidade de telas. Código, a pintura impede arbítrio de subjetividade, preceito de qualquer sorte ou convenção em geral. Reconhecida na tela, a luz da pintura é luz do olhar e, compartilhada, constitui-se como modelo da multiplicidade de reconhecimen- 
Kossovitch, L., discurso (20), 1993: 137-146

tos possíveis; análoga, assim, à Inteligência, a luz atribui-se, porém, à memória, que se produz como ato, não no tempo, mas no cruzamento de olhar e tela. 0 olhar que reconhece a luz indivisa é, simultaneamente, o que se reconhece no vestígio, surgimento da memória (no vestígio não opera visão alguma de pressuposição, que estabeleça, para ele, um antecedente, a marca: do imaginário, estase de visão supostamente havida, a marca é investimento de desejo anelante de originário). No reconhecimento, luz indivisa e luz mnêmica correspondem-se, no olhar, como pintura e vestígio, distinguindo-se ambas, distante a divergência de incompossíveis, como variaçōes de convergência: a correspondência é a de duas generalidades, a luz de tal tela, como indivisa, e a luz da memória, como múltiplos vestígios. Entende-se a convergência, na luz indivisa, como a abertura de que surgem os vestígios, e, na luz mnêmica, como a variação de vestígios, referidos à luz indivisa. A correspondência é dialógica, pois a generalidade da luz indivisa, abertura, e a convergência nela e nos vestígios, variação, sustêm sem paralaxe o olhar que atualiza, na pintura, os possíveis mnêmicos, com os quais a mesma luz indivisa se faz reconhecer iconograficamente; assim, a correspondência explicita, na senha, a passagem do olhar de luz a luz. Genérica, a luz indivisa é modelo, que não se eleva, participativa ou processionalmente, pois não se constitui como arquétipo ou hipóstase, não se podendo estabelecê-la como anterior ou exterior - superior - à luz mnêmica a ela correspondente: preso ao olhar, o modelo não se desprende do cruzamento, caindo arquétipo e hipóstase. No reconhecimento, operam, portanto, dois sentidos simultâneos do olhar: o da generalidade da luz indivisa, na qual se reconhece o vestígio; o do vestígio, pelo qual a luz indivisa se reconhece. Quanto à generalidade da luz indivisa que a constitui como modelo, ela é do infinito potencial: reconhecida, atualiza luzes mnêmicas compossíveis, pelas quais se faz reconhecer iconograficamente.

A luz da tela só é luz pelo olhar, mas são dela os elementos pictóricos que a fazem ser reconhecida. Como genérica, a luz indeterminada da tela é aperigráfica, porquanto, na pintura, a perigrafia legitima teologicamente a imagem bizantina como circunscrição canônica - nela legislando, icônica, a semelhança - do Figurado. A aperigrafia, indeterminação pictórica da luz indivisa, não se constitui, pois, como esquema (skhema = figura) que regule o olhar com 
forma prévia, determinação de convencionalismo que não se aplica à pintura de Claudino, Nada configurando, pois aperigráfica, a pintura não é da figura, nem o vestígio: indeterminados os correspondentes, luz indivisa e luz mnêmica, fecha-se a cena, barra-se o fantasma. Todavia, quando as telas de Claudino suscitam discursos emocionais, fica patente o desdobramento da luz mnêmica em vestígio e marca. No desdobramento, a marca é efetivação de um passado e o vestígio, de um presente, ambos estases temporais. Representado passado de um representante presente, a marca é cena fantasmática, com a tela se oferecendo como cenário de ocasião e o vestígio valendo como ingresso para o sujeito que se teatraliza. Fantasmada a marca como cena originária de luzes ocorridas, teatraliza-se um vivido, no qual o olhar é arrebatado por um sujeito narcísico de visão, escoando-se o ato, cruzamento, nos atos teatrais do tempo. Vampirizando o vestígio, a marca, efetivação de percepções, liga-se emotivamente à tela: o sujeito empossado na visão põe-se, emoções correntes, a discorrer, descrevendo, narrando, rememorante na cena da luz de fantasma, pela qual a luz indivisa da tela opera como sorte de efeito-Rorschach.

Mas a marca não insiste no vestígio (fazendo lembrar algum vivido), e o reconhecimento não consiste (na recuperação de algo perdido), pois ambos só diferem pelo imaginário, que os avança como estases temporais da representação. Não se produzindo, no cruzamento de olhar e tela, imaginário de memória, não há percepções originárias, emotivamente: nada insistindo, o vestígio é inconsistente, indeterminação. A determinação de tela, vestígio e olhar é obra religiosa do imaginário, que, propaganda da fenda mnêmica, religa a tela à cena. No cruzamento de olhar e tela, a senha é passagem do olhar de luz a luz, em duplo sentido. Nestes sentidos, o olhar, fazendo corresponder a luz indivisa e o vestígio, impede a intrusão de um terceiro, marca, percepção supositiva; como passagem, o olhar é visada, não rememoração de perspectiva cênica, e ato, não estase de tempo de rememoração. Como ato e visada, o olhar distingue-se da visão: heuristicamente, enquanto no mosaico bizantino a luz é da visão ascensional, estase de êxtase atemporal, na pintura, cruzando as tésseras, o olhar não é arrebatado por um alto-além, pois, intemporal. A senha de Claudino é a do olhar, das intensidades; achada, sua pintura é potência de achados: (h)eurísitca $=$ eureka . 
Assim, Claudino não pinta com forma, figura, limite, dimensão: a luz indivisa ultrapassa, no prefixo negativo, as determinações do pensamento pictórico da coisa e impede, impondo-se objetalmente, fantasmação narcísica na marca. Nele, a luz indivisa divide-se, divisionismo distante, em cubos: é a intensidade que vibra em suas telas, porquanto a pintura é descontínua na disposição geral. Como as telas não se pintam segundo princípio compositivo, fechamento, mas como distribuição de intensidades, nelas reverberam átomos, sequências, campos de cor: interação de cubos e fundos. Quando se pretende ter a forma, não a há, quando de motivo, este não está preestabelecido: o efeito é a luz indivisa. Cubo como técnica, senha como código, tessera significa, coextensivamente, distribuição na tela, pois seu terceiro significado é "dado", "jogo de dados": a pintura é lance de cubos. Os lances têm abertura, não de aleatório ou de infinito atual (com estes não haveria pintura em Claudino), mas de distribuição. Pois, intensiva, a pintura de cubos é distributiva, sendo a luz gerada de gradações, saltos, repetições. Quando com algo distinto das intensidades discretas o olhar topa, por exemplo, tal motivo, este não é mais que acessório, estase de continuidades, que, na geração da luz pelas cores, afirmase como resto distributivo. A tela, campo de intensidades discretas, atinge a máxima (que é mínima) claridade, incêndio (que é extinção), onde a singularidade irrompe: em tal lugar da distribuição, há desintensificação, interrompendo-se o jogo do olhar - identidade de cubo e fundo, apagamento de cubo por fundo, queima de cubo. Na distribuição, a luz é gerada como diferença de cor e, onde a diferença se extingue, a luz é cortada, o olhar pasma. A singularidade é a dos indiscerníveis, lugar de que a luz nasce e em que evanesce, limiar. O indiscernível não pertence à luz, pois é o seu outro adiacrítico, zero tesserário: deste nasce o olhar, extinta e reflexão, e neste se reflete sobre o olhar, apagada a luz. Singularidade, em que a reflexão se acha discursivamente adequada à pintura, heurística: máximo e mínimo tocam-se, revezamento de olhar e reflexão. A téssera que se confunde com o fundo é tessera rasa, generalidade bem achada pela pintura: tal téssera é pura superfície intelectiva, em que se embute uma reflexão possível, ziguezagueante e intermitente pela arte toda tesserária, cubo, senha, jogo, assim, técnica, iconografia, pintura, de Claudino. 
Abstract: José Claudino da Nóbrega's painting of light suggests a reflection on a heuristic basis: indivisible light and thing's light are analogously reflected in diverse doctrines and arts to be found in history. Justinian's Century is highlighted: the ekphraseis of panegyric, the articulations of metaphysics and, mainly, the golden mosaics which then are produced distinguish the tessera. At the same time cube, pasword and play, the tessera is the principal analogue of the painting of indivisible light as apposed to determined light.

Keywords: Light - tessera - painting - sight - reflection - heuristics - form - thing indivisibility - distribution - intensity. 